\title{
A reciclagem de materiais como processo de hibridismo cultural ${ }^{14}$
}

Renata Wilner

\section{Resumo}

A reciclagem de materiais é procedimento corriqueiro no ensino de artes visuais. É comum associá-la a valores ecológicos e econômicos. Aqui caberá refletir acerca das implicações propriamente artísticas, estéticas e culturais desse fenômeno, e sua abordagem pedagógica por tal viés. As operações de ressignificação de objetos industrializados descartados são enfocadas como hibridismo estético-cultural no contexto contemporâneo, em especial no meio urbano. A característica de hibridismo entre o industrial e o artesanal encerra a interculturalidade entre vários códigos - tradicionais, modernos, locais, microlocais (bairros, "tribos”, classes sociais, grupos étnicos), regionais, globais, midiáticos.

Palavras-chave: hibridismo cultural; reciclagem de materiais; meio urbano; arte-educação.

\section{Abstract}

The recycling of materials is commonplace procedure in teaching visual arts. It is common to associate it with economic and ecological values. Here it will be properly reflected on the implications of artistic, cultural and aesthetic of this phenomenon, and its pedagogical approach for such bias. Operations by reframing of discarded industrial objects are viewed as aesthetic and cultural hybridity in the contemporary context, especially in urban areas. The characteristic of hybridization between the industrial and artisanal ends interculturality between various codes - traditional, modern, local, microlocal (neighborhoods, "tribes", social classes, ethnic groups), regional, global, mediatic.

Keywords: cultural hybridity, material recycling, urban context, art education

14 Trabalho originalmente apresentado em comunicação no I ENREFAEB, no Polo UFF de Rio das Ostras, RJ, em 2009, no GT Ensino de Artes Visuais. Extraído da tese de doutorado da autora. 
O aproveitamento de sucatas em atividades escolares tem sido criticado como um fazer esvaziado de sentido ou abordado apenas no valor de educação ambiental, com pouca ênfase a um enfoque propriamente estético e cultural. Visando tal perspectiva, procuro analisar essa operação enquanto produto de interações culturais na complexidade do meio urbano contemporâneo. O fenômeno da reciclagem de materiais ou de ressignificação de objetos industrializados, de modo geral, é verificado tanto no ensino de arte, como na própria arte e no design, no centro ou na periferia do sistema artístico (considerados em relação aos fluxos de produção, exibição e consumo). Como exemplos, pode se mencionar casos com diferentes propósitos estéticos e inserções sociais e culturais.

Entre os objetos codificados na história da arte moderna e contemporânea enquanto obras de arte, encontram-se as assemblages cubistas e dadaístas, os ready-made de Duchamp, as obras do Novo Realismo francês, da Arte Povera italiana, do Neodadá, do Fluxus, até as montagens de instalações que se intensificaram a partir da década de 1980. Na arte brasileira, podemos citar os artistas Farnese de Andrade, Nelson Leirner, Barrão, Afonso Tostes e Ronald Duarte, que incorporam em seus trabalhos objetos descartados ou de uso cotidiano e fabricação industrial. $\mathrm{Na}$ área de design de mobiliário e artefatos utilitários, particularmente a produção dos irmãos Campana se apropria e ressignifica objetos produzidos artesanal ou industrialmente. Entre as produções periféricas ao sistema oficial ou comercial, além do artesanato urbano anônimo e difuso, podemos abordar os casos de Arthur Bispo do Rosário e de Gabriel Joaquim dos Santos, que construiu a Casa da Flor em São Pedro da Aldeia, RJ. Através dessa incompleta amostragem percebe-se a diversidade de estéticas, poéticas e intencionalidades proporcionadas por uma mesma operação, de apropriação e ressignificação de objetos industrializados - sejam eles em estado novo, usado ou deteriorado. O que já oferece subsídio para descartar a crítica da utilização de sucatas no ensino de arte como uma proposta meramente vazia de sentido.

\section{Apropriação, assemblage e ressignificação de objetos na arte moderna e contemporânea}

Dentro dos parâmetros da arte moderna autoral, erudita e destituída de função utilitária, é possível elencar alguns exemplos de apropriação e reconversão de significados de objetos industrializados.

Entre 1912 e 1914, Picasso iniciou uma pesquisa de construções escultóricas (relevos) com pedaços de madeira, papelão, papel, folha de zinco, cordão - bem toscos e crus (com pregos à mostra e pedaços de madeira sem acabamento) - que, segundo William Tucker (2001), consistiu no primeiro impulso libertário de temas (rompendo 
com a representação) e de materiais. Essas experiências profícuas influenciaram Tatlin e o construtivismo russo. Braque também realizou experiências escultóricas em papel, em 1912 (peças que hoje estão perdidas).

Após 1920, Picasso passou a trabalhar com ferro soldado, material mais durável, em colaboração com Julio González. Nesses trabalhos incorpora também objetos e peças do cotidiano, em assemblages como Cabeça de mulher (1929-1930), feito com coadores de metal, mola e peças de ferro, pintados. Em 1944, unindo apenas um guidão e um selim de bicicleta, Picasso criou a obra Cabeça de touro. Em ambas as obras, do período em que manteve contato com os surrealistas, pode se perceber um tema recorrente em Picasso: o das máscaras, que é coincidentemente significativo para nossa análise. A simbologia da máscara encontra correspondência com o próprio gesto da apropriação de objetos: sem deixar de ser o que é originalmente, o objeto se reveste "magicamente" de novos significados, a partir da sua inserção no contexto da arte, uma nova realidade que torna a primeira já inacessível diretamente.

O movimento Dadá trouxe outra perspectiva na incorporação de materiais e objetos retirados do cotidiano. Os ready-made de Duchamp eram escolhidos com indiferença estética entre uma infinidade de objetos industrializados e, nesse gesto extremo de despersonalização e destruição da narrativa da obra, denunciavam ironicamente a arbitrariedade e o fetichismo no campo da arte. As construções Merz de Schwitters, por sua vez, incorporavam objetos sem valor e descartados. A principal diferença entre Dadá e cubismo, ao lidar com os materiais prosaicos, é que os cubistas construíam uma espacialidade (ainda que deliberadamente fragmentada, reside o princípio compositivo), enquanto os dadaístas a destruíam por acumulação, ou, ao contrário, por esvaziamento através da negação de valor. Da vertente Dadá desdobraram-se poéticas que chegam aos dias de hoje, explorando as possibilidades de operar com objetos industrializados em geral, e com os descartados, em particular. Sem procurar reduzir tais propostas à escolha dos materiais, gostaria de sublinhar que este é um aspecto propositalmente realçado aqui, para compor o panorama da análise cultural em jogo.

As pesquisas de colagem e assemblage cubistas e dadaístas deram abertura para experimentações subsequentes, como a subversão do cotidiano através de uma gramática de estranhamento na conexão de objetos díspares na escultura surrealista (especialmente em Man Ray, Oppenheim e Joseph Cornell). Tais experiências visavam possibilitar ao observador um jogo de associações e metáforas através de fantasias pessoais.

O Novo Realismo francês, surgido na década de 1960, efetuou experiências com objetos prosaicos: Arman utilizava a estratégia da acumulação, enquanto César Baldaccini, a da compressão (esculturas feitas a princípio com peças e fragmentos descartados de automóveis - ruínas frescas de uma civilização industrial - e, posteriormente, com 
diversos materiais). Outra questão trazida simultaneamente foi a da fragilidade da matéria - por exemplo, na obra de Alberto Burri, precursora da Arte Povera italiana. Com trabalhos que incorporavam pedaços de sacos de aniagem rasgados, madeiras queimadas e ferro oxidado, Burri questionava a hierarquia dos materiais e a ideia de perenidade na arte. O Fluxus, o Neodadá e a Pop Art foram manifestações que desdobraram o gesto e ironia duchampianos, especialmente no contexto da sociedade estadunidense, onde o consumo de artefatos industrializados tornava-se sua marca cultural, na década de 1960. Devemos também levar em conta que o próprio Duchamp viveu em Nova York, de 1915 até sua morte em 1968, influenciando essa geração.

O crítico Pierre Restany (1979, p.82-83), captando as transformações que ocorriam na arte naquele período, assinalou tal processo como uma necessidade de transformação morfológica da arte na sua relação com o mundo:

As transformações morfológicas do mundo moderno nos solicitam, todavia, a todo momento. Para prestar contas de todos os desenvolvimentos, de todas as descobertas, de todas as mudanças, sentimos necessidade de ampliar nosso âmbito expressivo, levá-lo a um outro nível. Nossa compreensão do universo necessita daí em diante de abordagens mais imediatas e mais diretas. Os processos clássicos e os sistemas narrativos anteriores constituem um aparato demasiado pesado, e insuficientemente elástico, pois não resiste ao desencadeamento da afetividade criadora.

O homem de hoje é um homem ébrio de progresso e de velocidade e que pretende, ao se exprimir, completar e rematar sua conquista do mundo. A urgência expressiva identifica-se com a apropriação do real, sempre mais direta e mais total. No contexto da expressividade atual, os ready-made ganham novo sentido: eles traduzem o direito à expressão de todo um setor específico da atividade moderna, o da cidade, da rua, da fábrica, da produção em série. A jovem geração americana tinha de ser especialmente sensível a essa extensão do poder expressivo do objeto industrial.

\section{$[\ldots]$}

O gesto anti-arte de Duchamp carregava-se de positividade. O rea$d y$-made já não era o cúmulo da negatividade dadá, mas o elemento morfológico que servia de base para o estabelecimento de um novo repertório expressivo.

O ready-made já nasce híbrido, daí seu paradoxo, porque carrega uma informação prévia, alheia às idiossincrasias do artista - o valor da produção impessoal industrializada 
e a finalidade meramente utilitária, que é confrontada com códigos estéticos que lhe são estranhos e incorporados no gesto de transposição para o contexto da arte. Esse embate é um jogo intercultural, um choque semiótico, um processo de hibridação dos códigos catalisados pelo objeto transposto. Sua ironia é revelar que a "grande arte", essencializada por uma série de concepções metafísicas e elitizadas por discursos intelectualmente refinados, que promulgam sua autonomia, também é por si um meio híbrido.

Tal desenvolvimento do gesto fundado pelo ready-made e pela assemblage vem tomando corpo e abrangendo crescentemente as práticas artísticas, confirmando aquilo que Restany detectou como necessidade morfológica, diante da disponibilidade dos materiais em um mundo urbano industrializado, que configura a paisagem cultural com que o artista se defronta. Desde a década de 1980, tais práticas dominam a cena artística dos meios tridimensionais. Uma série de instalações do artista britânico Tony Cragg, por exemplo, consistiu em acumular fragmentos de objetos de plástico e agrupá-los por cor, criando arranjos de figuras (geralmente humanas em escala natural) no chão ou na parede do espaço expositivo, como um mosaico.

Entre os artistas brasileiros, podemos citar vários exemplos. Nelson Leirner, com uma produção diversificada desde a década de 1960, desloca objetos do uso cotidiano e apropria-se de elementos da cultura popular brasileira. Farnese de Andrade, a partir de 1964, criou objetos e assemblages com elementos coletados nas praias e aterros, ou comprados em lojas de objetos usados e depósitos de demolição, entre os quais: pedaços de bonecas, imagens religiosas, redomas de vidro, armários, oratórios e fotografias antigas da própria família, que combinava numa estética surrealista com uma densa carga expressiva. Barrão, em uma série de assemblages irônicas, reúne objetos domésticos, e em outra série, cria peças inusitadas colando pedaços de louça quebrada como bibelôs em formas de animais, xícaras, bules. Afonso Tostes elabora esculturas em diálogo com o espaço onde são inseridas, com madeiras recuperadas de demolições e canteiros de obras, e Ronald Duarte, além das ações em espaços públicos, tem uma produção artística com garrafas PET.

\section{Casos periféricos ao sistema de arte: a produção de Bispo do Rosário e a Casa da Flor de Gabriel Joaquim dos Santos}

De modo análogo ao desafio de Duchamp (que simulou ser um outsider da arte, refugiando-se no mundo do enxadrismo e jogando com discursos e operações "anti-artísticas”), podemos lembrar casos em que está presente o gesto de ressignificação de objetos - especialmente dos descartados - em práticas que a princípio não eram consideradas artísticas nem pelo autor, nem pela sociedade, tendo uma posterior incorporação nos códigos de arte a partir das percepções renovadas pelas tendências contem- 
porâneas, a partir da década de 1960. Entre tais casos, destaca-se o de Arthur Bispo do Rosário, cuja estética contém afinidades com várias vanguardas mencionadas: a ideia de acumulação de Arman, o questionamento do valor material da Povera, a arte conceitual, a elaboração de um mito pessoal (cujos arquétipos fundamentam a "obra"). Ficamos tentados a comparar, por exemplo, sua Roda da Fortuna à Roda de Bicicleta de Duchamp. Mas inserir Bispo do Rosário em códigos restritos da arte seria trair o confronto que sua obra exerce sobre uma sociedade cujas regras foram responsáveis por sua condição de exclusão; seria eliminar o paradoxo de uma leitura que se quer também híbrida e avessa às cristalizações conceituais. Leitura híbrida que opere, mais que com uma arte do inconsciente (ou arte dos loucos), com o inconsciente da arte.

Interessa particularmente assinalar os processos e os materiais constituintes da poética de Bispo do Rosário: recolhia até os mais vulgares objetos - sucatas, embalagens, vasilhames, farrapos dos uniformes - no lixo da Colônia Juliano Moreira, no Rio de Janeiro, onde esteve internado em condição de isolamento por cinquenta anos. Essa matéria prima era agrupada e reutilizada. Os restos de panos eram desfiados e bordados, dando origem a textos e desenhos em mantos e estandartes. Nenhum objeto à volta de Bispo parecia escapar de sua "captação" do universo, que se dizia incumbido por Deus de registrar e reordenar: pentes, escovas de dente, canecos de alumínio, talheres, tudo era agrupado, numerado, "inventariado" e disposto sobre painéis que Bispo chamava de "vitrines". Desta forma, a "missão divina" de reconstruir o universo a partir de um mundo que é dado num entorno caótico (a loucura seria um espelho, que reflete e inverte?), da reorganização de seus signos (incluindo as palavras) em uma nova sintaxe, criando com ela uma narrativa intersticial e não linear, metaforiza o caráter do fazer artístico.

Fragmentos do cotidiano em restos inutilizados e abandonados também estão presentes nos cacos e cacarecos que compõem a Casa da Flor. Obra de bricolagem arquitetônica, foi construída em estrutura de pau-a-pique e pedras a partir de 1912, em São Pedro da Aldeia (litoral do Estado do Rio de Janeiro), por Gabriel Joaquim dos Santos (1892-1985), trabalhador semi-analfabeto das salinas da região, que nunca frequentou uma escola. De 1923 a 1985 (ano de seu falecimento), Gabriel foi incorporando, em sua casa, materiais recolhidos no lixo doméstico e no refugo de obras de construção civil, segundo ele, guiado por Deus através de sonhos. Cacos de cerâmica, de louça, de vidro, de ladrilhos, velhos bibelôs, lâmpadas queimadas, conchas, pedrinhas, correntes, tampas de metal, manilhas, faróis de automóveis e outras "quinquilharias" eram garimpados em montes de detritos. Esses materiais davam origem a ornamentos externos e internos (em formas orgânicas, representando vegetais como flores, folhas e frutas), a esculturas e colunas com figuras fantásticas, e ao próprio mobiliário da casa (estante, bancos, armários). Gabriel dos Santos usava técnicas de alvenaria e mosaicos para agregar os diversos elementos. 
Tão intrigante quanto a produção de Bispo do Rosário, a carga expressiva da Casa da Flor aglutina estéticas próximas de Gaudí, do barroco e do surrealismo, mas o gesto da coleta de material no lixo e sua aplicação na arquitetura remete à Merzbau de Schwitters, embora não se baseie na indiferença niilista dadá. Este tipo de classificação estilística é apenas um vago exercício acadêmico, ainda distante da realidade orgânica a brotar espontânea e continuamente das mãos de Gabriel Joaquim dos Santos: enquanto ele viveu, a casa era um organismo vivo em permanente transformação. O teor onírico e lúdico do seu processo era sintetizado em suas próprias palavras: "Esta casa não é uma casa, isto é uma história, é uma história porque foi feita por pensamento e sonho”. ${ }^{15}$

\section{A ressignificação de objetos no design dos Irmãos Campana}

Assim, como ocorre o fenômeno da ressignificação de objetos industrializados por um artesanato anônimo e disperso, esses materiais também aparecem em produtos de design autoral, como os móveis e objetos utilitários dos irmãos Fernando e Humberto Campana. Seus projetos são híbridos em vários sentidos: incorporam o artesanal ao industrial (um processo onde são previstas etapas artesanais na produção industrial, invertendo o artesanato popular que aproveita materiais industriais); aglutinam o design e a arte, tanto em termos de processo criativo quanto de fruição do público (como obras de arte, as peças possuem títulos e expressam conceitos e relações metafóricas possuem uma preocupação com o significado que vai além da funcionalidade da peça, assim como uma elaboração formal escultórica); o cotidiano e elementos da cultura popular são mesclados a códigos eruditos de arte; combinam materiais nobres com simples, comuns e baratos; materiais industriais e naturais (vime, galhos de jabuticabeira, bambu) são unidos em várias peças.

O caráter experimental e artesanal do trabalho dos irmãos Campana gerou, no início da carreira (final da década de 1980) algumas peças únicas ou produções em quantidade limitada, com uma qualidade mais artesanal que industrial. Uma peça emblemática da dupla é a cadeira Favela (1990), feita com pedaços de sarrafos encontrados na rua, rusticamente sobrepostos com pregos aparentes.

Junto a estruturas tubulares de alumínio, aço inoxidável ou ferro, os irmãos Campana agregam materiais simples e comuns, de pouco valor comercial, que conferem justamente o caráter inusitado e um toque de humor: tal qual espécies de ready-made às avessas, subvertem seu próprio desvalor, através da força estética do rigor formal a que são submetidos. Cadeiras, poltronas, mesas, biombos, luminárias, fruteiras são feitos

15 Depoimento de Gabriel Joaquim dos Santos, recolhido pela pesquisadora Amelia Zaluar. Disponível em: $<$ http://www.casadaflor.org.br/depoimentos.htm>. 
com cordões de algodão, papelão corrugado, pedaços de madeira, carvão, mangueira plástica, plástico bolha, tiras de feltro, retalhos de tecido e de plásticos coloridos, borracha E.V.A., papel de seda; e compostos por objetos como martelos de borracha, ralos de P.V.C., bichos de pelúcia, bonecas de pano.

Em depoimentos à imprensa, os irmãos Campana admitem que foi necessário um processo de adaptação entre os processos de fabricação industrial e de fabricação artesanal. Objetos onde existem materiais trançados, emaranhados ou entrelaçados (como mangueiras plásticas, cordões e antenas de TV), fizeram com que a indústria incorporasse um trabalho manual. Fernando Campana declarou: "Durante todo esse tempo eu acho que a gente foi criando um diálogo, uma aproximação: entendendo também os processos industriais e fazendo a indústria entender o processo artesanal". ${ }^{16}$

A cadeira Favela e outras peças traduzem uma identidade brasileira não tanto pela temática, mas pelo que Fernando Campana define como "caráter de descobrir beleza onde não tem" - a mesma sensibilidade que movia Gabriel Joaquim dos Santos, ao transformar cacos e detritos, a princípio feios, em formas intrigantemente belas na Casa da Flor (característica presente de forma peculiar em cada uma das outras manifestações acima mencionadas). E também, como na Casa da Flor, mas em outro modo, ciclo e registro, as criações dos irmãos Campana contêm uma organicidade, "um caráter de imprecisão e imperfeição", um dado não racional nesses emaranhados de fios ou sarrafos anarquicamente justapostos, que se contrapõe, de certa forma, à lógica industrial, e que escapa ao controle do desenho projetado. Fernando Campana o define como "caos ordenado", o que nos remete também analogamente ao processo de Bispo do Rosário, em termos de intencionalidade.

O espírito bricoleur e a ludicidade assumida dos Campana são detonadores do processo criativo interagindo com seu ambiente. Em entrevista a Julana Monachesi (2007), Humberto Campana declarou:

Sempre tem um paralelo com uma coisa de infância, aquele inconformismo de criança que pega os brinquedos e começa a revirar. Eu e o Humberto fizemos isso, não de desmontar, de ser professor Pardal, mas pegar os objetos e ficar imaginando no que eles poderiam se transformar: pegar o despertador, virar e fazer um disco voador.

16 CAMPANA, Fernando, entrevista para MONACHESI, Juliana. (Colaboração para a Folha de S.Paulo). Confira entrevista com os designers Fernando e Humberto Campana. Folha Online (postado em 28/07/2007). Disponível em: <http://www1.folha.uol.com.br/folha/ilustrada/ult90u312713.shtml>. Acessado em: $15 / 10 / 2008$. 
É uma experiência de tentar mudar o estado das coisas. É como olhar isso aqui [aponta o tampo da mesa feito de ralos de plástico] e começar a pensar: o ralo não serve só para escoar água, você pode comer no ralo. Acontece muito de, quando a gente vai produzir uma peça, ela ganhar uma perversidade depois, o conceito vem depois.

O jogo de transmutação de significados, a partir de uma fantasia pessoal despertada pelas características morfológicas dos objetos, traz esse caráter infantil em que o lúdico e o perverso se expressam, através da subversão da ordem das coisas. O que se torna ainda mais significativo pelo fato de dois irmãos estarem "brincando" juntos.

Por causa desse teor transgressivo, os irmãos Campana enfrentaram resistência por parte da indústria nacional em produzir seus projetos. O processo nômade de fabricação da cadeira Favela, por exemplo, ilustra essa contradição acentuada pelo percurso que acabou tomando em um mundo de capital globalizado. Em 1990, apenas duas cadeiras Favela, que eram protótipos produzidos no estúdio dos Campana, foram vendidas a 500 reais cada. Em 2008, a peça já era produzida pela empresa italiana Edra e vendida por 3000 euros. O consumidor brasileiro tem que importar um produto concebido por designers nascidos na cidade de Brotas (interior de São Paulo) e fabricação italiana, com mão-de-obra brasileira da região das Missões (Rio Grande do Sul), em Santo Ângelo (cuja comunidade de 3000 habitantes é de origem alemã), e que ironicamente tem a favela como signo de representação. Como bem assinala Peter Burke (2003), o hibridismo não deve só ser celebrado, mas percebido em um problemático campo de relações de forças desiguais (neste caso, econômicas e culturais). Fernando Campana lamenta que os brasileiros tenham, mediante os caminhos tortuosos do mercado globalizado, que pagar caro pelo produto.

O hibridismo dos irmãos Campana também diz respeito a suas referências e métodos de coleta de material físico e simbólico, em atento contato vivo com a urbe (por exemplo, em caminhadas pelo centro de São Paulo). Maria Helena Estrada (2003) assinala que em seu processo de criação, "Fernando e Humberto andam pela cidade, são atraídos por vendedores de rua e por lojinhas de bric-a-brac, tiram do cotidiano popular a inspiração para suas criações, percorrem o mundo e retornam para o campo, para Brotas, a cidadezinha onde cresceram".

\section{Aproveitamento de materiais no artesanato urbano}

Notamos a atenção dos irmãos Campana às heranças do artesanato tradicional e à incorporação do artesanal ao processo industrial de fabricação de móveis e utensílios. Esses procedimentos peculiares da dupla encontram eco em práticas anônimas de apropriação e reciclagem de materiais. No meio urbano, podemos observar produções 
por diversos segmentos sociais com aproveitamento de retalhos, jornais, revistas, pneus, latas, garrafas PET (politereftalato de etila), papelão, embalagens plásticas e de isopor. Esses materiais se transformam em bonecas, colchas, almofadas, tapetes, móbiles, lamparinas, funis, vasos de plantas, cestos, caixas, móveis e outros utensílios.

Em ensaio publicado na revista Artesanias del Brasil (1995), Rosza vel Zoladz detecta uma reconversão de usos e significados dos objetos, com qualidades ambivalentes de permanência e transformações em sua morfologia. A ambiguidade de sentidos dos objetos feitos com material reciclado advém da memória do uso e significado original, em contraste com o novo destino do objeto, a partir de sua apropriação transformadora pelo artista ou artesão. A reconversão de formas e funções a partir da reciclagem de materiais diz respeito à adaptação de saberes tradicionais a contextos urbanos e a materiais industrializados, congregando o plano material e o imaterial na produção de artefatos culturais. Podemos assinalar, portanto, a característica de hibridismo cultural presente nos objetos industrializados que são ressignificados em processos artesanais e artísticos. De modo geral e como princípio, Canclini (2003, p. 2) define hibridação como "processos sócio-culturais nos quais estruturas ou práticas discretas, que existiam de forma separada, se combinam para gerar novas estruturas, objetos e práticas".

No caso dos artefatos produzidos com sucatas, verificamos o hibridismo entre o tradicional (ou arcaico) e a modernidade industrializada. Maffesoli (2008, comunicação oral) resgata o sentido etimológico original da palavra derivada de arché - raiz -, designando o que está na base subterrânea do social, que é "radical" enquanto pensamento fundado no vivido, nutrido pelo "húmus", substância simbólica, configurando alicerces invisíveis. Tal enraizamento, na sua organicidade, é dinâmico, e remete a um imaginário coletivo. A vitalidade do cotidiano, do mundo superficial aparente e de seus rituais, é nutrida pela invisibilidade profunda das raízes. Assim, o sentido de arcaico não seria exatamente o de uma retrospecção, mas de uma prospecção. O arcaico, no caso das práticas artesanais, se dá através dos modos de compartilhamento das técnicas, sem tabu com a cópia, tornando determinadas criações anônimas e difundidas no grupo (ou entre diversos grupos, com o alcance dos meios de comunicação, além das possibilidades de transporte e visibilidade dos produtos no meio urbano). A despreocupação com o valor de autoria une as pontas do arcaico e do contemporâneo. Para Maffesoli (2007, p. 45-50), "tecnologia e arquétipos convivem bem, [...] há uma sinergia do arcaico com o desenvolvimento tecnológico", o que coloca entre parênteses a hipótese de Canclini (2000) sobre "entradas e saídas da modernidade". O moderno é incorporado, deglutido pelo arcaico.

Como o processo de reconversão se dá através da utilização de métodos e estratégias artesanais anônimas, próprias da estética popular pré-moderna, utilizando-se de materiais modernos, industrializados, podemos dizer que o dado moderno se torna memória, enquanto o arcaico é o elemento transformador presente, que o suplanta 
através de apropriação e ressignificação. A interferência do artesanal sobre o industrial, invertendo a lógica da produção em série e o destino funcional planejado do objeto, bem como substituindo o descarte pelo aproveitamento do material, constituem os valores de hibridismo agregados pelo processo aos produtos.

Entretanto, a classificação da produção de artefatos através do aproveitamento de sucatas em uma estética popular é complexificada pelo contexto cultural multifacetado do meio urbano, que torna as classificações maleáveis. $\mathrm{O}$ acesso a mostras, museus ${ }^{17} \mathrm{e}$ imagens de obras de arte veiculadas por diversas mídias (eletrônicas, digitais ou impressas), a exibição de objetos com design artístico em vitrines de lojas e a circulação de imagens publicitárias evitam que se possa falar em guetos culturais na cidade. O que ocorre é uma interculturalidade de múltiplos códigos, através dos quais diferentes interpretações e reconversões criativas engendram a produção e os usos de uma variedade de artefatos.

Em suma, a multiplicidade estética urbana flui e gera contaminações, por meio das quais ocorrem ressignificações, apropriações, reconversões. Essa dinâmica se dá de forma assimétrica, dependendo da direção dos fluxos em relação aos grupos produtores e consumidores: produção popular para consumo popular; produção popular para consumo turístico; produção popular para consumo das camadas médias e elevadas locais; produção das camadas médias e elevadas para consumo das próprias; produção das camadas médias e elevadas para um mercado internacional; produção de designers profissionais para consumo popular ou de massa. Há que observar que alguns desses fluxos são dispersos e multidirecionais, tornando a análise mais complexa que o encaixe nessas categorias.

\section{Dos múltiplos deslocamentos e hibridizações dos artefatos-signos aos contextos de arte-educação}

A característica em comum, assinalada entre os vários casos acima citados, reside na utilização de materiais do cotidiano, fabricados industrialmente, em variações de estado (novos, usados, descartados como lixo, inteiros ou quebrados). Duchamp e Picasso, através da assemblage e do ready-made, promoveram gestos fundadores que abriram caminho para explorar o universo dos objetos industriais enquanto fonte material de arte. Rompendo com a tradição do fazer artístico de modo que técnica, representação, suporte e matéria-prima deixam de serem as vias de constituição da linguagem, pode-

17 Os programas educativos de museus e espaços culturais, com atendimento de visitas de grupos de escolas públicas tem particularmente contribuído para ampliação ao acesso direto de camadas populares a exposições de arte. 
-se considerar, principalmente no caso de Duchamp (já que Picasso ainda tinha uma preocupação plástica construtiva), tal ato como uma transgressão radical. Seu caráter fundador, portanto, advém de que a transgressão propiciou uma renovação dos códigos da arte. Estabelecidos esses novos códigos, abriu-se um leque de possibilidades ainda em curso na arte, no artesanato e no design contemporâneos.

Seja na produção artesanal anônima, ou nos registros de arte autoral, o uso crescente da apropriação de artefatos industriais (incluindo a imagem eletrônica, digital e impressa), em detrimento de técnicas tradicionais, como a pintura de cavalete e a escultura a partir de matéria-prima bruta (que persistem com renovação estética influenciada pelo cenário geral), indica nada mais que uma sensibilidade do tempo. Artistas não usam mais esse tipo de material como veículo de transgressão (ou seja, não é esta característica por si mesma, como o foi em Duchamp, que determina o caráter transgressor de uma obra), senão o oposto: agem dentro dos códigos vigentes, ou seja, em coerência com a sociedade em que vivem - urbana e materialmente industrializada. Qual seja a postura do artista, crítica ou celebratória, o sentido de sua obra se insere em uma paisagem cultural, opera com dados da sua realidade histórica, com a disponibilidade material e simbólica do tempo e espaço em que vive.

A presença de materiais banais do cotidiano - objetos produzidos anonimamente em série para consumo em massa - entra em choque com o valor áurico que envolve miticamente a criação artística e seu produto, a obra de arte. De Duchamp a desdobramentos posteriores, os artistas tiram partido crítico da carga irônica que emana desse choque. Essa interpenetração entre o "áurico", o massivo e o tradicional popular torna as produções artísticas contemporâneas múltiplas e híbridas.

A multivocalidade dos artefatos híbridos, a contradição entre o áurico e o não áurico, e entre o arcaico e o moderno, dizem respeito à impossibilidade da síntese dialética, que corresponderia a um fechamento em uma forma conciliatória e totalizante, eliminando as contradições que lhe deram origem. Ao contrário, a contradição e o conflituoso estão no cerne do hibridismo: há uma incompletude e um multifacetamento que Canevacci (1996) chama de "dialética sincrética". Portanto, não há melting pot, caldeirão cultural, onde a mistura resultaria em uma forma única, mas a sua imagem correspondente seria a do mosaico, ou da salada:

O que a dialética sintética limpa, ordena, supera, a dialética sincrética suja, desordena, mistura, fragmenta e sobrepõe. Transfere. No sincretismo cultural, a montagem ou a colagem cabem na própria metodologia da pesquisa e da representação. A hibridação das culturas favorece a proliferação de possíveis dialéticas-patchwork, onde os tecidos policromos ("retalhos" reciclados), com os quais repre- 
senta o evento cultural, coexistem sem superações. (CANEVACCI, 1996, p. 39)

Ironicamente, a forma como objetos corriqueiros são convertidos em arte potencializa o valor áurico e autoral da obra. Isso ocorre nas produções valorizadas por sua singularidade, incluindo a Casa da Flor, a obra de Bispo do Rosário ou a dos irmãos Campana. O desprestígio do material, por contraste, realça o valor da inteligência artística na operação de ressignificação, contribuindo para reforçar a mística do autor de tal façanha mágica ao converter o cotidiano comum ou até o renegado (lixo) em arte.

Em suma, os jogos metafóricos, metalinguísticos e associativos propiciados pela utilização de objetos cotidianos na arte é uma operação espaço-temporal. O objeto é portador de um valor no universo cotidiano, que através de sua transposição para a linguagem artística, torna-se memória. Ocorre então uma metamorfose de natureza semiótica, que se dá por ambiguidade entre a memória do objeto e o novo contexto em que é inserido, recodificando-o. Sua posição espacial (Duchamp, por exemplo, alterava a posição convencional dos objetos ao transformá-los em ready-made), sua inserção ambiental, sua combinação com outros objetos ou sua disposição para a relação com o observador conformam a moldura cultural em cujo "círculo mágico" ocorre uma transposição de valor simbólico e significado do objeto. A interferência no signo original é uma espécie de contracomunicação.

Embora com outro destino final, tal processo não se diferencia do aproveitamento dos materiais no artesanato urbano contemporâneo: há uma reconversão de significados e usos - no caso dos objetos legitimados como arte, para função puramente estética e apartada do cotidiano; no caso dos objetos artesanais reciclados, agrega-se à estética, a finalidade utilitária nova, de forma que o objeto é reconduzido ao cotidiano, em novo uso e forma. Em ambos os casos, a ação humana - que transforma o objeto e lhe atribui novos significados - é a marca do corte temporal entre a memória e o novo, ambivalentemente portados nesses objetos.

Mais que uma entronização do objeto, as estratégias de reconversão operam criticamente e colocam no centro do processo o ser humano, e é de sua diversidade cultural que advém a possibilidade de engendrar hibridações, nesses trajetos entrecruzados. Há que advertir, no entanto, que esses processos são abertos e nunca o todo se completa: sempre fica algo de fora (que não se deixa hibridizar), como também fica faltando algo, ou seja, a hibridação não chega a nenhuma síntese, sua "dialética sincrética" (nos termos de Canevacci), vai se reordenando em novos arranjos, incorporando novos elementos e abandonando outros, e se estrutura numa sintaxe complexa e em movimento contínuo no fluxo das relações sociais. 
Portanto, a fim de contextualizar o uso de sucata em projetos artístico-pedagógicos, torna-se necessário uma articulação com tais procedimentos fora do ambiente de instituições educacionais, em um meio social mais amplo. Assim, o conhecimento da aplicação da reciclagem de sucatas - em obras de arte, produtos artesanais para uso cotidiano, cenografia, carnaval, moda - pode ampliar os sentidos de sua utilização na escola e em outros contextos pedagógicos, através de vínculos afetivos, cognitivos e identitários. Em sua significação culturalmente codificada, as características de hibridismo - embora tornem complexos os sentidos contidos nos processos de fabricação, nas soluções morfológicas e metamorfoses dos objetos - facilitam com relação às múltiplas possibilidades de nexo com a diversidade cultural urbana.

A ampliação da significação também suscita um incremento de possibilidades de experimentação com os materiais. Ainda que o motivo da opção pela utilização de sucatas seja o da precariedade de recursos materiais, há que considerar o desafio criativo e estético ao se lidar com a incompletude e com o imprevisível. Exercita-se o estar disponível diante do disponível, estimulando a exploração de potencialidades insuspeitadas nas qualidades dos objetos e suas transformações pela criatividade humana.

A reciclagem de materiais, portanto, ultrapassa o que poderia denominar-se "estética do precário", para tornar-se um desafio às possibilidades de combinações de usos, significados, funções e formas, revelando-se excelente exercício criativo, movido, conforme Zoladz (1995, p. 216), pela "incessante busca de satisfação da Kunstwollen; o desejo de beleza se expressa no fazer". Sua utilização vai além do discurso ecológico e econômico, quando adquire relação com os conteúdos propriamente artísticos, cujo foco não deve ser perdido, enquanto objeto específico desse campo disciplinar.

Há também que assinalar considerações acerca do corte crítico efetuado pelas operações de aproveitamento de materiais industrializados descartados. Os objetos são aí consumidos através de uma reversão do mercado e do fetiche da mercadoria, já que há o aproveitamento do residual desse mercado. O próprio processo de produção é revertido: produz-se para o próprio consumo (no caso do contexto educacional), transformando o indesejável (lixo) em desejável. ${ }^{18}$ Ao reconsumir o que deixou de ser consumido, mediando esse processo por ação própria, elimina-se também a alienação da atividade produtiva.

No contexto da arte-educação, podemos resumir a densidade contida nas operações de ressignificação e transformação das sucatas através de reflexões de Walter Benjamin (2002) acerca do caráter subversivo da criança, aliado ao aspecto de prazer, na sua

18 No caso analisado na pesquisa de doutoramento, tratava-se da confecção de brinquedos. 
perversidade infantil: ela não se contenta com as coisas como são dadas, tem necessidade de quebrar e remontar, por exemplo, ou simplesmente alterar os signos através da fantasia.

Significa dizer que, da ludicidade infantil ou adulta, às bricolagens caseiras e anônimas, até práticas profissionais de artesanato e arte, é possível inserir procedimentos alternativos e críticos em relação aos fluxos dominantes de produção e circulação de mercadorias, marcados pela descartabilidade e pela ideologia de consumo voraz e incessante. As operações de ressignificação de objetos industrializados descartados constituem, portanto, possibilidades de negociar e subverter os significados e usos atribuídos aos artefatos e impostos à sociedade.

Particularmente, é interessante observar o aproveitamento de materiais industrializados descartados como constituinte de criações estéticas das classes populares, e sua utilização no contexto educacional dessas mesmas classes. Para o professor de arte, tal estratégia torna-se também uma importante alternativa diante da precariedade de recursos materiais nas escolas públicas. Observa-se que não é esta precariedade que constitui o fator determinante da qualidade do trabalho, e sim o preparo do professor e as interações no ambiente da aula. Inclusive porque as poéticas contemporâneas não se fundamentam sobre o valor do material, mas na operação conceitual que se faz com qualquer material - que pode até ser o próprio corpo do artista, ou o corpo social, ou ainda a mensagem veiculada e compartilhada com acréscimos participativos em diversos meios, como o eletrônico.

Tomamos as manifestações artísticas legitimadas pelo sistema oficial de arte não como modelo, mas como uma entre outras manifestações de poéticas e processos de criação. Assim como as considerações aqui colocadas pressupõe uma desierarquização dos materiais, urge corresponder uma desierarquização dos produtores e seus processos, reconhecendo a multiplicidade estética dos diversos grupos socioculturais, e nas relações de interação entre eles. Considera-se, para o efeito dos argumentos apresentados, o artesanato não como uma "arte menor", mas sua característica de saber coletivo aceita como arte legítima; ao mesmo tempo, sem formulações essencialistas e compreendido na dinâmica histórico-social, o que possibilita a inclusão dos artefatos produzidos por grupos urbanos com materiais industrializados.

Desta forma - percebendo os artefatos como materiais disponíveis na vida contemporânea, e os sujeitos não apenas como consumidores, mas como potenciais autores coletivos e individuais que recriam sentidos para tais materiais -, espera-se contribuir com percepções e reflexões sobre práticas corriqueiras e talvez insuficientemente exploradas, de utilização de descartes de produtos industrializados em contextos de arte-educação. 


\section{Referências bibliográficas}

bAUDRILLARD, Jean. O sistema dos objetos. São Paulo : Perspectiva, 1993.

BENJAMIN, Walter. A obra de arte na era de sua reprodutibilidade técnica. In: Magia e técnica, arte e política: ensaios sobre literatura e história da cultura. Obras Escolhidas. Vol. 1. São Paulo, Brasiliense, 1994.

. Reflexões sobre a criança, o brinquedo e a educação. São Paulo : Duas Cidades;

Ed. 34, 2002.

BURKE, Peter. Hibridismo cultural. São Leopoldo, RS : Editora Unisinos, 2003.

CANCLINI, Néstor García. Culturas híbridas: estratégias para entrar e sair da modernidade.

São Paulo : EDUSP, 2000.

. Noticias recientes sobre la hibridación. TRANS - Revista Transcultural de Música,

n. 7, 2003. Texto apresentado como conferência no VI Congresso da SIBE (Sociedad de Etnomusicología), em Faro, julho de 2000.

Disponível em: <http://www.sibetrans.com/trans/trans7/canclini.htm\#top1> Acesso em: 09/01/2008.

CANEVACCI, Massimo. Sincretismos: uma exploração das hibridações culturais. São Paulo

: Studio Nobel : Instituto Cultural Italo Brasileiro - Instituto Italiano di Cultura, 1996.

CARVALHO, Abelardo de. Arthur Bispo do Rosário.

Disponível em: <http://www.twister.com.br/artesacra/bispo.htm>.

ESTRADA, Maria Helena. Os Campanas. São Paulo : Editora Bookmark, 2003. [Excerto] in: Irmãos Campana: Brasileiros na vanguarda do design internacional. In: Zona D. Disponível em: <http://www.zonad.com.br/zonad/noticia.aspx? Node=458>.

FARIA, Fabiana Mortosa. Arthur Bispo do Rosário e seu universo representativo. $<$ http://www.urutagua.uem.br/005/12his_faria.htm>. Revista Urutágua - revista acadêmica

multidisciplinar. Centro de Estudos Sobre Intolerância - Maurício Tragtenberg, Departamento

de Ciências Sociais, Universidade Estadual de Maringá (UEM). Maringá, PR, 
publicada em 03.12.04.

MAFFESOLI, Michel. Conferência: A comunicação no quadro das ciências sociais, hoje. Biblioteca Nacional, Rio de Janeiro, 10/09/2008.

O ritmo da vida: variações sobre o imaginário pós-moderno. Rio de Janeiro :

Record, 2007.

O tempo das tribos: o declínio do individualismo nas sociedades de massa. Rio de Janeiro : Forense Universitária, 2000.

MONACHESI, Juliana. Confira entrevista com os designers Fernando e Humberto

Campana. (Colaboração para a Folha de S. Paulo). Folha Online (postado em 28/07/2007).

Disponível em:<http://www1.folha.uol.com.br/folha/ilustrada/ult90u312713.shtml $>$. Acessado

em: 15/10/2008.

RESTANY, Pierre. Os novos realistas. São Paulo : Perspectiva, 1979.

RICHTER, Ivone Mendes. Interculturalidade e estética do cotidiano no ensino das artes visuais. Campinas, SP : Mercado das Letras, 2003.

TUCKER, William. A linguagem da escultura. São Paulo : Cosac \& Naify, 2001.

WILNER, Renata. Interculturalidade na experiência do Programa de Extensão Educacional

Núcleo de Arte da Secretaria Municipal de Educação do Rio de Janeiro. Tese (Doutorado). Rio de Janeiro : UFRJ / PPGAV-EBA, 2009.

. Precariedades no ensino público de arte no nível fundamental. Da precariedade. Anais do XIII Encontro do Programa de Pós - Graduação Em Artes Visuais / EBA UFRJ,

2006. 1 CD-ROM.

ZALUAR, Amelia. Depoimento de Gabriel Joaquim dos Santos, recolhido pela pesquisadora.

Disponível em: <http://www.casadaflor.org.br/depoimentos.htm>.

ZONA D. [Online]. Irmãos Campana: Brasileiros na vanguarda do design internacional. Disponível em: <http://www.zonad.com.br/zonad/noticia.aspx?Node=458>. 
ZOLADZ, Rosza W. vel. El reciclaje de materiales. In: DAMATTA, Roberto et alli. Artesanías

del Brasil. Revista Artesanías de América, n 46-47, Centro Interamericano de Artesanías y

Artes Populares (CIDAP) / Coordenação de Folclore e Cultura Popular - FUNARTE / MinC,

agosto de 1995, p. 209-219. 